\title{
晚更新世以来罗布泊盐湖的 沉积环境和找钾前景初析*
}

\author{
郑绵平齐文 \\ (中图地质科学院矿床地质研究所, 北京 100037) \\ 吴玉书 \\ 刘俊英 \\ (中国科学院植物研究所, 北京 100044)（中国地质科学院地质研究所, 北京 100037)
}

\section{关调罗布泊盐湖、沉积环境、找钾前景}

1989 年 10 月完成罗布泊部份地区野外调查,穿插两条路线(图 1), 首次从“耳轮”西北角

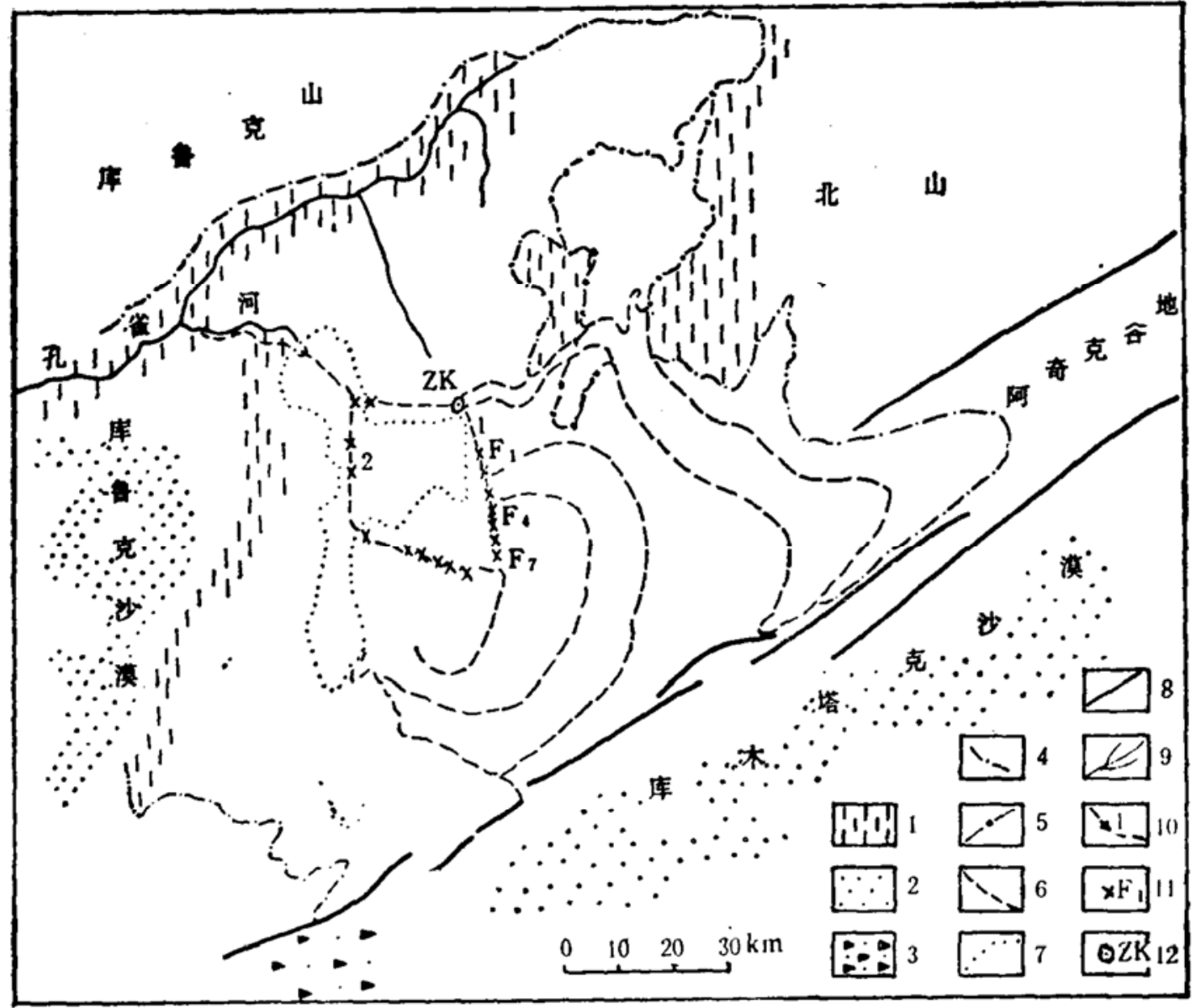

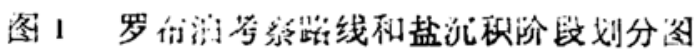

1. 雅丹;2. 沙漠;3. 戈壁;4.罗布泊湖相沉积范围;5.第一阶段盐沉积区;6.第二阶沙基 沉积区;7.“新湖”沉积区;8.断裂;9.水系;10.考察路线;11.堔坑;12.钻孔

本文 1990 年 12 月 24 日收到.

“地质的产部直管易特别找矿项目，并得到中国地质科学院部分资助. 参加野外调查还有郑元等同志. 
深人盐売区约 $38 \mathrm{~km}$, 施沾一口, 挖浅坑 17 个, 系统地采集各类沉积样品, 获得珍贵的第一手 野外资料,首次划分出三个盐沉积阶段, 确定有微量的钾石盐和光卤石等钢矿物的存在. 通过 对晚更新世晚期以来罗布泊湖盆演化和沉积环境分析, 对罗布泊成钾远景作了较全面论述.

\section{一、盐沉积阶段的划分}

根据卫星照片解释和本次考察, 罗布泊地表盐沉积大致划分为三个阶段 (图 1):

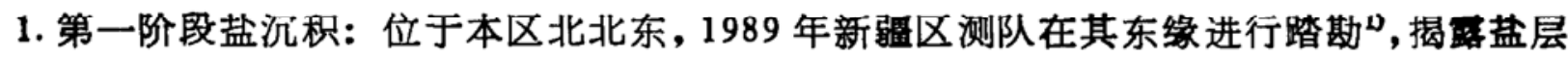
厚度 $1.5-2.2 \mathrm{~m} . \mathrm{KCl}$ 含量一般在 $0.02-0.32 \%$, 局部地带较高; 孔隙备水距地表 $1.6-2.3 \mathrm{~m}$, 含 $\mathrm{KCl} 0.68-1.87 \%$.

2. 第二阶段盐沉积：面积较大,在卫星照片上显示出深浅相间的半环带“耳轮状”影象. 经 本次考察, “耳轮区”西北部的盐沉积很薄, 厚仅 $20-30 \mathrm{~cm}$. 该盐层含钾量较高, 据所查的 20 个 盐样,含 $\mathrm{K}^{+} 0.055-1.72 \%$, 平均 $\mathrm{K}^{+}$含量 $0.446 \%$ 。经鉴定主要盐类矿物有石盐、石青, 局部 为钻艺硝, 含微量钾石盐、光卤石等. $\mathrm{F}_{4}$ 孔隙卤水含 $\mathrm{KCl} 10.8 \mathrm{~g} / \mathrm{L}$, 埋深 $4.5 \mathrm{~m}$, 且流量很小, 但盐层有自西北往东南、南方向缓慢增厚的趋势.

3. 第三阶段盐沉积: 沉积范围小, 主要分布“新湖”区,盐沉积很薄,一般 $10-30 \mathrm{~cm}$, 较松 散. 6 个盐样分析结果, 含 $\mathrm{K}^{+} 0.23-1.07 \%$, 平均 $0.66 \%$.

\section{二、沉积环境探讨}

以浅坑 $F_{4}$ 为代表 (图 2), 将该区自晚更新世晚期以来沉积环境大致划分为 $\mathrm{V}$ 个沉积时 期:

I. 沉积时期,深 4.5-3.75m, 未见底,为灰红-棕黄色的杂色段, 含碳酸盐粘土一粉砂粘土 层, 部分具纹层, 有少量檤状石高和孔隙卤水, 在底部找到咸水种介形虫化石 Cyprideis littoralis (Brady) 等, 反映湖水较深, 并已威化. 本段狍粉以麻黄 (Ephedra)、蓠 (Artemisia)、 荃 (Chenopodiaceae) 占优势为特征, 反映湖周围为荒漠植被类型, 气候干旱、温和. 根据在 $3.9 \mathrm{~m}$ 处 ${ }^{14} \mathrm{C}$ 测年为 $17480 \pm 300 \mathrm{a}$ B.P., 结合孢粉特征, 此时期应属于晚更新世晚期.

II. 沉积时期, 深 3.75- $2.13 \mathrm{~m}$, 棕色段,为粘土粉砂与含高粘土层. 粉砂含量较前剧增,具 分散石高. 反映湖水水体动荡, 为氧化环境. 本段未找到介形虫化石, 孢粉含量很少, 推测湖 周围仍为荒漠植被类型, 气候凉干. 根据沉积率和狍粉特征, 此时期应属于晚更新世末期.

III. 沉积时期,深 $2.13-1.87 \mathrm{~m}$, 灰绿色段,为含高粘土,产分散石峦板晶、高镁方解石、白 云石等. 含微量孔腺攴水和分散状石盐, 已为盐水湖,偏碱性. 该层段含介形虫较多, 主要有 咸水种 Cypridies littoralis (Brady), Cyprinotus sp. 以及能在超盐度卤水中生存的喜盐种 Eucypsis inflata (Sars) $)^{[1]}$, 反映湖水已成为卤水. 沉积物中孢粉含量不多、类型单一, 主要 为耐干旱的灌木麻黄和草本植物蓠、蔡类型, 推测植被仍为荒漠类型, 气候温干. 据上下层 ${ }^{14} \mathrm{C}$ 测年以及孢粉和介形虫特征, 此时期应属于早全新世.

IV. 沉积时期,深 $1.87-0.78 \mathrm{~m}$, 暗色段,为黑、灰黑至灰褐色含高粘土或淤泥, 产石高板 晶, 局部含有机碳稍高, 反映为盐水湖, 湖水稳定, 偏碱性. 本层段不含介形虫化石. 孢粉组合

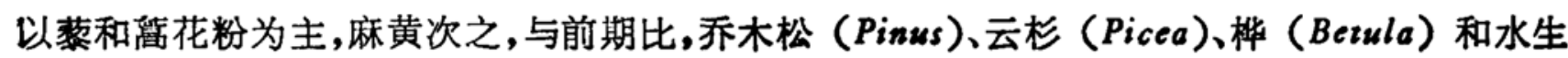

1）据新疆地质矿产局第一区测队资料. 


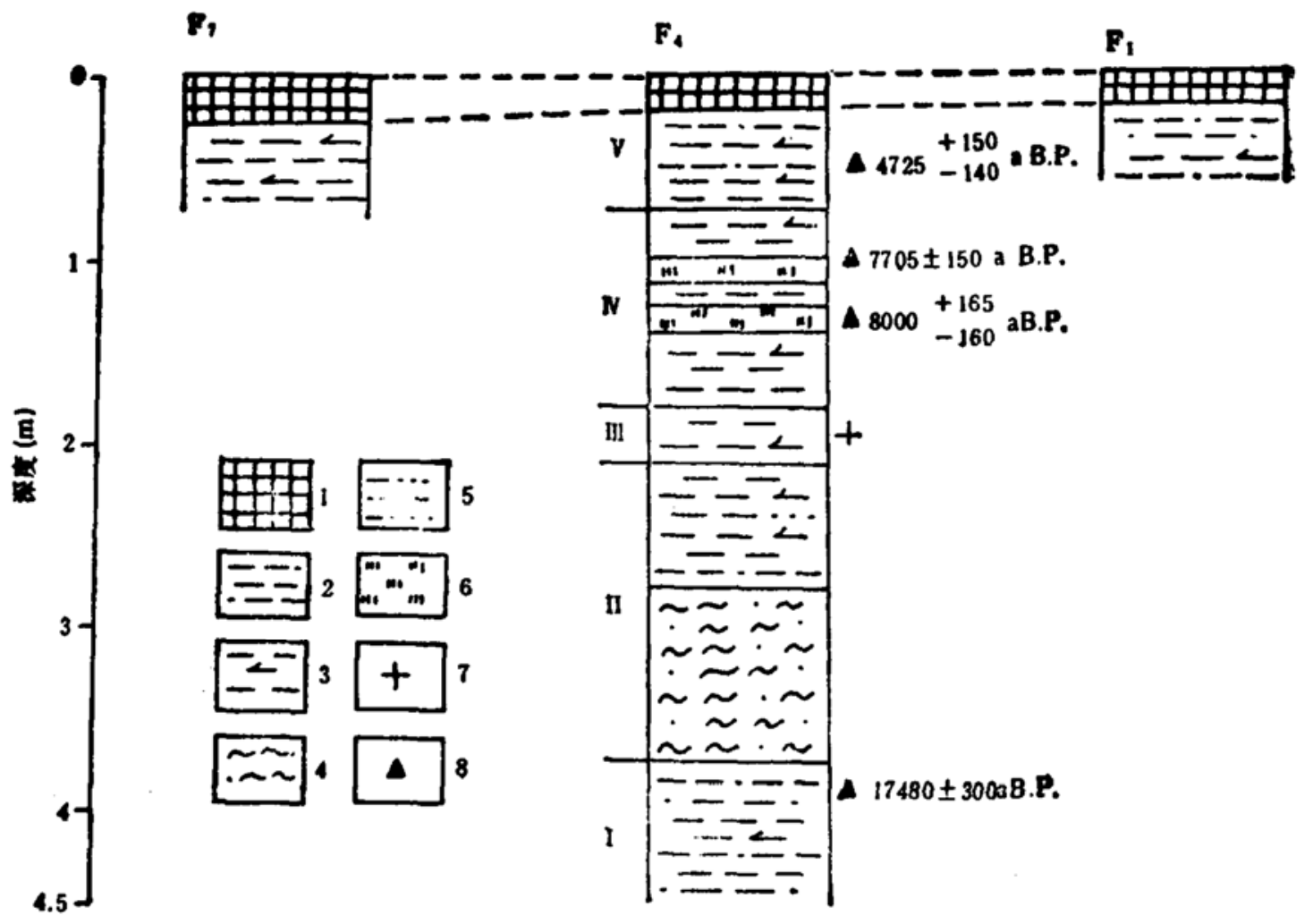

图 2 考察路线 1 部分探坑剖面对比图

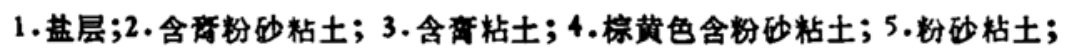

6.含青洨泥;7.含分散状石賉;8. ${ }^{4} \mathrm{C}$ 测年

植物香满 ( Typha ) 花粉数量增多, 说明湖周植被主要为荒漠类型, 但在离湖不远处, 可能有 小片林, 湖水面也有所扩大. 反映气候比前期较潮湿和温暧. 在本段深 $1.3 \mathrm{~m}$ 处的淤泥 ${ }^{14} \mathrm{C}$ 测

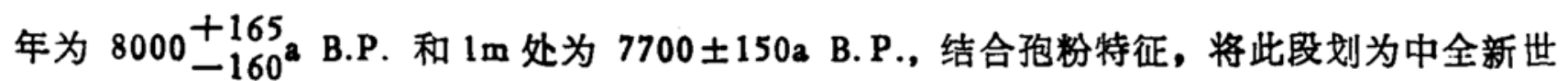
沉积. 并推测罗布泊地区大西洋期开始较早, 这一认识有待进一步工作。

V. 沉积时期, 深 $0.78-0 \mathrm{~m}$ 岩性为含青碳酸盐粘土一石盐沉积。表层盐壳厚 $23 \mathrm{~cm}$, 反 映罗布泊已达干盐湖阶段,地表干涸沙化. 本段未找到介形虫, 孢粉是以灌木和草本植物麻

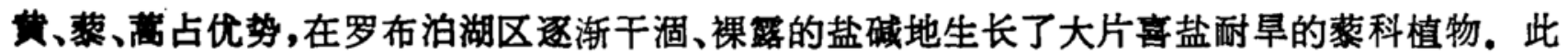
时气候干旱多风. 由于近期人类的活动, 加速了罗布泊盐湖的干涸. 在下部 $0.5 \mathrm{~m}$ 处 ${ }^{14} \mathrm{C}$ 测年

为 $4725+155^{2}$ B. P., 结合孢粉特征, 本殷应属于晚全新世沉积.

\section{三、找钾前最初析}

罗布泊盐壳面积达 $20000 \mathrm{~km}^{2(20)}$ ，居全国盐老区之首．在第一、二盐沉积阶段均已发现有 钾盐矿物存在, 个别卤水样含钢达到工业品位, 表明具有含钾的广泛性. 但目前已查地段的地 表盐壳沉积只具有广而薄的特点, 其卤水储存量和涌水量小, 而不具工业意义. 然而据成盐地 质条件分析, 罗布泊广泛分布的钾分具备一定的聚集条件: (1)第三纪以来, 罗布泊曾长期成 为塔里木盆地的汇水中心, 包括罗布泊在内的塔里木盆地具有悠久的成盐地质历史, 从第三纪 至第四纪有大量盐沉积形成, 并经过多次化学分异, 使钾、镁组分相对集中. 因此, 具备较丰富 的盐类和钾分物质来源. (2)与柴达木盆地西部钾盐湖相对应, 罗布泊基底断块具有由东北向 
西南逐渐沉䧄的特征. 第一、二阶段盐沉积中心均具有向西南迁移的趋势,盐湖地表高程也具 有北高南低的特点, 因此,罗布泊地下卤水埋深也有北深南浅的特点, 且南缘红发现丰富的㷋 卤水 ${ }^{[2]}$. 按照多级盐湖成盐模式, 易溶性钾镁盐类受重力场和化学分异作用控制, 具有向低处 汇聚的规律性 ${ }^{[3]}$. 因此, 在第一、二沉积阶段低陷部位很可能有丰富的含钾卤水聚㫦. 同时通 过遥感图象的数字处理, 其结果与地质的推测相一致, 在第一盐沉积区龟背山南的局部区域和 第二盐沉积区 (“耳轮区”) 南部凹陷部位, 均有地下卤水层的显示。

因此,现阶段仍需进一步野外地质工作验证. 由于罗布泊中南部的盐壳起伏较大,用一般 交通工具(汽车)难于进人而无法探索该盐沉积中心卤水层及其含钾性. 建议用其它现代化工 具,包括直升飞机和性能良好的机动浅钻等, 尽早对罗布泊中南部有找钢前景地段进行现场钻 探、验证.

\section{参考文埱}

[1] 杨留法等,海洋湖沼通报, 1982,1: 20-28.

[2]中国科学院新逼分院罗布泊综合科学考家队,罗右泊科学考察与研究,科学出服社, 北京, 1987 .

[3] 郑缩平等, 需藏高原盐湖, 北京科学技术出版社,北京, 1989 . 